\section{Severe, Long-Lasting Symptoms from Doxycycline-Induced Esophageal Injury}

Tetracycline derivates (especially doxycycline) are among the most common causes of medication-induced esophageal injury (1). This condition is characterized by single or multiple ulcers in the midesophagus resulting in retrosternal burning pain associated with dysphagia and odynophagia $(1,2)$. These symptoms are often selflimiting and in most cases resolve within days to a week. We observed severe and long-lasting esophageal injury due to doxycycline in three patients. All were female patients with pelvic inflammatory disease, and the symptoms described above appeared between the second and seventh day of treatment. Esophagoscopy revealed friable mucosa with exudates and ulcers in the mid-esophagus (Figure 1). The symptoms were so severe that none were able to ingest anything orally and thus had to be hospitalized for parenteral nutrition (average hospital stay: 7 days). The pain resolved 2 to 5 weeks after its onset. We also noticed discordance between the severity of the patient's symptoms and findings on esophagoscopy. If present, ulcers were small. The major endoscopic findings were exudates that involved relatively short segments of the esophagus. These were quite mild compared to the more severe findings in other forms of esophagitis, in which symptoms are not as disabling as in our patients. In conclusion, doxycycline-induced esophageal injury may present with severe symptoms, and the course may be long lasting (up to six weeks). Considering the discordance between severe symptoms and relatively minor endoscopic findings, motility disorders along with the direct injury may be involved in the pathogenesis of this condition.

1. E. Tankurt, H. Akbaylar; Y. Yenicerioglu, I. Simsek, O. Gonen Department of Internal Medicine, Dokuz Eylül Medical Center, Inciralt, Izmir, Turkey

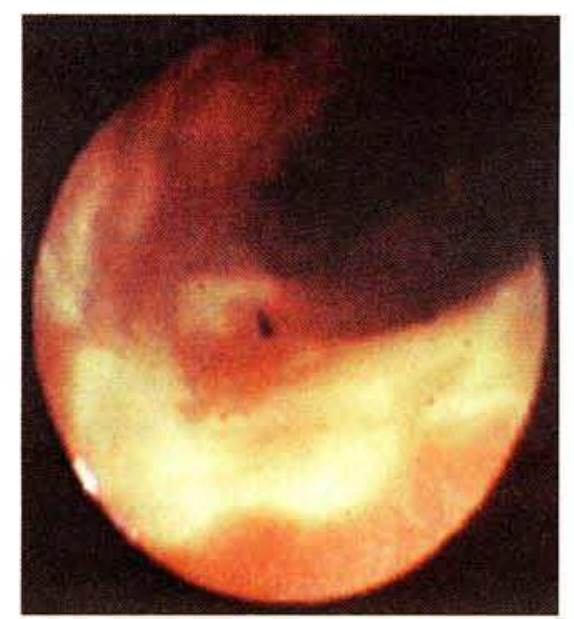

Figure 1: Esophagoscopic view of the circumferential exudates in the midesophagus.

\section{References}

1. Bott $S$, Prakash C, McCallum RW: Medication-induced esophageal injury: survey of the literature. Am J Gastroenterol 1987; 82: $758-763$

2. Kikendall $J W$, Friedman AC, Ovewole MA, et al:: Pill-induced esophageal injury. Dig Dis Sci 1983; 28: 174-182.

Corresponding Author

H. Akbaylar, M.D.

Department of Internal Medicine

Dokuz Eylül University Medical Center

Inciralt, Izmir 35340

Turkey 